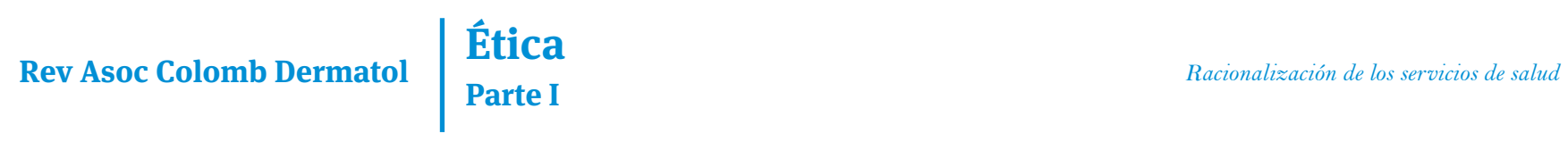

\title{
Racionalización de los servicios de salud
}

\author{
José María Maya ${ }^{1}$
}

\section{RESUMEN}

Presentación de un caso de toma de decisiones de asignación de recursos de salud en una situación de crisis, donde la oferta de camas y recursos de la unidad de cuidados intensivos (UCI) no alcanzan para atender la demanda desbordada por una pandemia. Se presentan y analizan los diferentes criterios propuestos por los miembros del equipo de salud y se cuestiona la decisión finalmente tomada por el director de la institución de fijar como criterio de priorización para asignar camas, ventiladores y demás recursos de UCI por estricto orden de llegada de los pacientes, independientemente de su situación de salud y de sus posibilidades de recuperación. Se hace un análisis desde la ética de cuál sería el criterio más adecuado para priorizar la atención de los pacientes cuando hay un desfase entre recursos y necesidades o solicitudes.

PALABRAS CLAVE: ética; racionalización; criterios; priorización; recursos salud.

\section{TITLE}

\section{SUMMARY}

Presentation of a decision-making case for the allocation of health resources in a crisis situation, where the supply of intensive care unit (ICU) beds and resources are not enough to meet the demand overwhelmed by a pandemic. The different criteria proposed by the members of the health team are presented and analyzed and the decision finally made by the director of the institution is questioned, to set as a prioritization criterion to allocate beds, fans and other ICU resources in strict order of arrival of patients, regardless of their health situation and their chances of recovery. An analysis is made from ethics of what would be the most appropriate criteria to prioritize patient care when there is a gap between resources and needs or requests.

KEY WORDS: Ethics; Rationalization; Criteria; Prioritization; Health resources.

1. Médico, magister en Salud Pública, magister en Dirección Universitaria y magister en Dirección y Gestión de la Seguridad Social; profesor titular, Universidad CES; decano general, Escuela de Ciencias de la Vida. Universidad EIA, Medellín, Colombia ORCID https://orcid.org/oooo-0003-3721-7572

Correspondencia: José María Maya; email: josemariamayamejia@gmail.com

Recibido: 20/07/20; aceptado: $21 / 07 / 20$

Cómo citar: Maya JM. Racionalización de los servicios de salud. Rev Asoc Colomb Dermatol. 2020;28(2): 120-121. DOI:

Financiación: ninguna, conflictos de interés: ninguno 


\section{PRESENTACIÓN DEL CASO DE ÉTICA N ${ }^{0} 12$}

En un hospital de tercer y cuarto nivel de atención de una ciudad surge una gran preocupación por el incremento de pacientes que padecen una patología pandémica con grave afectación de su salud, que hace necesario ser internados en la unidad de cuidados intensivos (UCI) y conectarse a un ventilador. Como el incremento de los casos hace prever que la demanda desbordará la capacidad institucional de atención y que en algún momento habrá que decidir a qué pacientes se ingresa a la UCI y se conectan a un ventilador y a cuáles no se les puede prestar el servicio con la alta probabilidad de que fallezcan, el director de la institución reúne a su equipo médico para consultarles con qué criterio se haría la priorización para la asignación de los recursos escasos.

Algunos médicos proponen que se utilice el criterio de utilidad social, es decir, cuando hay que decidir entre uno u otro paciente, se asignarán los recursos al que sea más útil para la sociedad, ya sea por su conocimiento o tipo de cargo que ocupa. Otros médicos proponen se asignen según el criterio de responsabilidad que el paciente haya tenido con su salud. Los recursos deben asignarse al paciente que trató de cuidarse de manera responsable y no al que no siguió las normas de comportamiento para evitar contagiarse. Otro grupo proponen que se adopte el criterio de contribución del enfermo al sistema de salud. El paciente que aporte más recursos para el sistema de salud o el que pague seguros complementarios o pólizas de salud o quien pague más impuestos debe recibir con preferencia en la atención que aquel que no aporta y pertenece al régimen subsidiado o su contribución es muy pequeña. Otros médicos proponen el criterio de edad y solicitan se asigne los recursos a las pacientes más jóvenes y se nieguen los recursos a los más ancianos o a los mayores de 70 años. Por último, un grupo propone que se asignen según estricto orden de llegada al hospital independientemente de cualquier otra consideración.

El director busca lograr un consenso entre sus colegas para decidir un criterio único que permita orientar la asignación de los recursos, pero la discusión no logra encauzarse para alcanzar este objetivo. Como sabe que debe tomar una decisión rápidamente, se orienta por la última propuesta y decide que en su institución los recursos de cama de UCI y ventilador se asignarán por estricto orden de llegada, independientemente de la edad, el sexo, la gravedad, la presencia o no de comorbilidades, la utilidad social o la responsabilidad.

La decisión se empieza a implementar con mucha resistencia por parte del personal de salud y críticas de la comunidad usuaria de los servicios de salud, que se sienten lesionados en sus derechos, cuando un familiar se agrava y fallece por no recibir los servicios de cuidado intensivo dado que otros pacientes llegaron primero que él a la institución.

\section{CUESTIONAMIENTOS ÉTICOS}

1. ¿Todos los pacientes por su dignidad humana tienen el derecho a recibir los tratamientos que requieren para salvar o mejorar la calidad de su vida?

2. Cuando los recursos de salud no alcanzan para todos los pacientes, ¿es ético aplicar criterios para priorizar a quién se atiende primero?

3. ¿Cuál es el criterio más adecuado para realizar la asignación de los recursos de salud insuficientes?

4. ¿El criterio de edad puede ser un criterio único para asignación de recursos?

\section{Puntos clave}

- $\quad$ La salud bien meritorio.

- Criterios de asignación de recursos.

\section{Ética continúa en la página 192}

